\title{
Erratum
}

\section{Erratum: Mattan et al., Motivation Modulates Brain Networks in Response to Faces Varying in Race and Status: A Multivariate Approach (eNeuro July/August 2018, 5(4) e0039-18.2018 1-13 https://doi.org/10.1523/ENEURO.0039-18.2018)}

In the article "Motivation Modulates Brain Networks in Response to Faces Varying in Race and Status: A Multivariate Approach," by Bradley D. Mattan, Jennifer T. Kubota, Tianyi Li, Tzipporah P. Dang, and Jasmin Cloutier, which appeared as e0039-18.2018 in the July/August 2018 issue, a production error led to a superscript number ' 3 ' being included at the end of the title. In addition, the author's rebuttal to the synthesis was not included in the HTML version of the article. The article has been corrected accordingly. These corrections do not affect the conclusions of the paper.

https://doi.org/10.1523/ENEURO.0373-18.2018 